\title{
Transmission topologies for the integration of renewable power into the electricity systems of North Africa
}

Originally published as:

Bernhard Brand (2013):

Transmission topologies for the integration of renewable power into the electricity systems of North Africa

In: Energy Policy, vol. 60, pp. 155-166

DOI: 10.1016/j.enpol.2013.04.071 
Bernhard Brand $^{a}$

\section{Transmission Topologies for the integration of renewable power into the electricity systems of North Africa}

a Wuppertal Institute for Climate, Environment and Energy, Germany

* Corresponding author: Bernhard Brand, Wuppertal Institute, Döppersberg 19, 42103 Wuppertal, Germany

E-mail: bernhard.brand@wupperinst.org

Phone: +49 202-2492-109

Fax: +49 202-2492-108 


\section{Abstract}

A cost-minimizing electricity market model was used to explore optimized infrastructures for the integration of renewable energies in interconnected North African power systems until 2030. The results show that the five countries Morocco, Algeria, Tunisia, Libya and Egypt could together achieve significant economic benefits, reaching up to $€ 3.4$ billion, if they increase power system integration, build interconnectors and cooperate on joint utilization of their generation assets. Net electricity exports out of North Africa to Europe or Eastern Mediterranean regions, however, were not observed in the regime of integrated electricity markets until 2030, and could only be realized by much higher levels of renewable energy penetration than currently foreseen by North African governments.

\section{Introduction}

The tremendous growth in demand for power is one of the principal challenges faced by the electricity sector in North African countries. By 2030, the entire region bordering the southern shore of the Mediterranean Sea - from Morocco to Egypt - will be consuming 2.0-2.4 times more electric energy than it is presently (OME, 2011), and only massive investments into new generation capacity, paralleled by reinforcements of the transmission infrastructure, can avert supply shortages and subsequent damages to the countries' economic development. Undoubtedly, the pressure to keep up with the soaring demand for electricity is placing great strain on the North African economies, especially in times of political upheaval in the aftermath of the Arab Spring and an imminent worldwide economic crisis. However, an accelerated upgrade of electricity infrastructures also offers outstanding opportunities: North African countries can step out of their accustomed national planning strategies and reshape their electricity supply and transmission systems in a more sustainable and coordinated manner.

\subsection{Opportunities for power system integration and renewable energies}

One major opportunity arising from the pressing need to upgrade North African electricity systems is the creation of a coordinated strategy among the different national power sectors and the setup of strengthened transnational interconnectors for electricity exchange. Until recently, electricity system planning in the southern Mediterranean region has focused on 
national power demands; this is why today only weak cross-border capacities connect the North African countries. The few existing transmission lines are only sporadically utilized, serving mainly for unscheduled energy transfers ('mutual aid') to counter temporary supply shortages - rather than for systematic, market-based electricity trade (MED-EMIP, 2010). Looking back at the historical development in Europe, the current status of North Africa's power systems can be compared with the European situation in the 1960s and 1970s, when the development of interconnectors was still driven by system security and reliability requirements. Larger cross-border electricity transmission only started in later decades, before finally reaching today's levels on liberalized European power markets (ECN, 2006). A similar evolution of power system integration also would have multiple advantages for North Africa: power exchanges over large distances can level out structural differences between the countries' electricity markets due to different fuel prices, power plant operation costs, and load patterns ${ }^{1}$. Regions with low electricity production costs benefit from export revenues, while importing countries avoid additions of expensive generation capacity. Furthermore, interconnected power systems are more robust against network failures, unforeseen load increases and tripping of power plants, and hence require a lower reserve capacity, rendering the utilization of installed power plants more efficient. As a further advantage, cross-border integration allows access to a more diverse mix of primary energy sources for electricity generation, which consequently increases energy supply security in the interconnected regions.

A second opportunity, closely linked to the issue of transmission infrastructure, is the increased utilization of renewable energy sources (RES-E). As is commonly known, the entire southern Mediterranean area is endowed with excellent solar and wind resources. Particularly in North Africa, renewable energies promise important strategic benefits given their potential to reduce energy dependency and to slow down the extraction of oil or gas reserves. Interconnected electricity systems facilitate the integration of RES-E by bridging regional heterogeneities of intermittent renewable power. Transmission system operators (TSO) could jointly forecast renewable feed-in and organize the dispatching of conventional power plants to balance out variations of solar and wind generation across larger geographical areas. With RES-E technology costs constantly decreasing, renewable power is garnering greater attention

1 Due to their specific industry structure and household behavior, the typical load profiles of North African countries show significant differences on a daily and seasonal basis. Likewise, worth mention are the distinct weekend concepts applied by the countries (Saturday/Sunday weekends vs. Friday/Saturday weekends) and the time shift of electricity consumption across the Southern Mediterranean rim, which stretches over three time zones. 
across the entire Middle East and North African (MENA) region. The recent RES-E expansion goals, and even detailed roadmaps, that many governments have embraced are clear indications of this trend (see section 4.5.).

\subsection{Transcontinental context and institutional developments}

In addition to the above-mentioned opportunities for North African power systems there is the aspect of pan-Mediterranean cooperation. Already in 1995, with the Barcelona Process, a framework was created for economic collaboration between the European Union (EU) and its southern neighbors, targeting improved integration of southern Mediterranean energy markets with those of the EU. These activities received a fresh impetus in 2008 with the founding of the Union for the Mediterranean (UfM), a more formal political partnership between the EU members and 16 southern Mediterranean countries. UfM's principal institutional vehicle pertaining to energy issues is the Mediterranean Solar Plan (MSP), a project dedicated to improving the political and regulatory conditions for a future trans-Mediterranean electricity system based on renewable energies (MSP, 2011). The concept, which is being advanced by private sector initiatives like the Desertec Industrial Initiative (Dii, 2012) and the Med-Grid consortium (MedGrid, 2012), is indeed unique in the history of power systems. This is not only because of the technical challenges, but also because of the ambition to reunite two structurally, completely disparate electricity systems: in the North, the already well-integrated and fairly liberalized European power system, characterized by relatively stable electricity demand and the political will to reduce greenhouse gas emissions; in the South, the fragmented national electricity markets, often ruled by state monopolies whose main occupation is to cope with the ever-increasing electricity demand.

Despite these apparent differences, a number of recent developments indicate that the convergence of Euro-Mediterranean electricity systems is being taken seriously on the institutional level. In 2007, national regulatory agencies from both sides of the Mediterranean founded MEDREG, the Association of Mediterranean Regulators for Electricity and Gas (MEDREG, 2012). The year 2012 brought the creation of a similar multilateral body, the umbrella organization of the Mediterranean Transmission System Operators (MED-TSO), with the objective to coordinate the development and operation of Mediterranean electricity grids (MED-TSO, 2012). 
On a more regional level, attempts to spur electricity system integration are visible in the North African Maghreb region: the electricity ministers of the Arab Maghreb Union ${ }^{2}$ have cooperated since 1989 within the Maghreb electricity committee Comité Maghrebin de l'Electricité (COMELEC). Three COMELEC members -Morocco, Algeria, and Tunisiaalready operate a synchronized and interconnected electricity grid (Brand and Zingerle, 2010) and are striving for a progressive integration of their electricity markets and the implementation of joint transmission projects (Algiers Declaration, 2010). Similar activities have been established in the Mashreq, where an eight-country electricity agreement between Egypt, Iraq, Jordan, Lebanon, Libya, Palestine, Syria, and Turkey was initiated in 1988 (ADB, 2012). The Arab Union of Electricity (AUPTDE, 2012), founded under the auspices of the League of Arab States, has likewise subscribed to the idea of fostering the coordination of their members' electricity systems, including the strengthening of transnational transmission capacities.

\section{3. $\quad$ Barriers}

Despite such multiple activities, the development of integrated MENA electricity systems still faces a number of challenges and barriers. One particular obstacle is the high investment cost of transnational transmission assets, and the question how these costs can be allocated among the concerned parties. Financing transnational transmission projects still requires - directly or indirectly - negotiations between the involved governments, which is one important reason why projects between North African countries are constantly plagued by delays and why interconnector capacities are still insufficient today. Moreover, though not often openly discussed, many governments in North Africa have political reservations against too much interdependence with their neighboring energy sectors (Ghiles, 2010). Energy is a sensitive area in MENA politics: Many governments view increased dependence on neighboring nations or diminished control, even partly, of domestic resources -for instance, through electricity imports- as a serious loss of national sovereignty. General reservation regarding cooperation can also be observed when looking at the renewable electricity goals of the North African countries; so far, none of the national roadmaps envisages RES-E synergies with its neighbors, although the different geographical and temporal availability of wind, solar, and hydro power would speak strongly for a joint and coordinated utilization of these resources.

2 The Arab Maghreb Union (AMU) was founded by the governments of Algeria, Libya, Mauritania, Morocco, and Tunisia. 


\subsection{Research questions}

The present paper sets out to unfold and quantify some of the major effects of increased cooperation and integrated power system planning among North African countries. In particular, the following questions are addressed: (1) What are the economic benefits of an increased multilateral cooperation with regard to electricity exchanges via transnational interconnectors? (2) How would increased RES-E integration influence the electricity generation scheme and the transmission topologies between the North African countries? (3) Under which circumstances could rising renewable energy penetration in North Africa facilitate electricity exports to neighboring regions; e.g., to Europe?

The analysis was performed using a multi-regional electricity market model that simultaneously optimizes investments in generation and transmission capacities, as well as power plant dispatch and electricity exchanges between different countries. The study begins, in section 2, with a description of the article's scope within the research context of power system modeling of interconnected North African electricity markets. This is followed by a model description (section 3), and a definition of the parameters and scenarios (in section 4). Finally, sections 5 and 6 provide the analysis of the results and a concluding discussion.

\section{Scope of the study}

Modeling renewable energy integration into interconnected North African electricity systems is a relatively young research area that has been addressed by only a few publications. So far, many studies have been largely motivated by the vision of cross-continental power networks, considering Europe and the MENA region (EU-MENA) as one large interconnected system, substantially -or even fully- supplied with renewable power. A drawback of these (normative) approaches is that they often omit analysis of the transformation pathways from the current fossil-based power supply infrastructures into the future. Additionally, the needs and particularities of North African electricity markets are often not sufficiently considered in the research.

Czisch (2005) used a linear optimization model to simulate a cost-minimized, transcontinental $100 \%$ renewable electricity supply scheme on the basis of HVDC transmission. In his study, however, the North African electricity systems were only represented in a relatively coarse manner, with several countries merged into simplified model regions. A more clear-cut regional analysis is provided by Dii (2012), simulating a 90\% RES-E supply in 2050 for the 
entire EU-MENA region, made up of 38 different countries, including the five North African countries as distinct model regions. Unlike Czisch's work, Dii's study features detailed transmission corridors, including both $\mathrm{AC}$ as well as HVDC transmission technology. Both studies, however, remain idealized, as they simulate a hypothetic, newly built generation and transmission system (Greenfield approach), neglecting the existing generation and transmission infrastructures (power plant inventory and transmission lines) as boundary conditions of the analysis. Haller et al. (2012) also explored the temporal transition of the EUMENA electricity systems over several decades. Here, the investment pathways for generation and transmission assets were optimized under the assumption of strong carbon emission reduction targets until 2050. Power system data of the North African countries, however, was only approximated. A study providing greater insight into North African power infrastructures and their individual electricity generation preferences is provided by Mercados (2011); but this work does not include transmission capacity optimization and is regionally limited to the Maghreb countries Morocco, Algeria, and Tunisia.

The analysis presented in this paper aims to provide a realistic picture of what can be done in terms of power system development in North Africa from today until 2030, taking into account the existing infrastructures and different national planning strategies in North Africa, but also considering technical and non-technical barriers to electricity system planning and the integration of renewable energies. The following key specifications were considered paramount for the model development:

- Capability to simulate different power system transformation scenarios from today until 2030.

- Inclusion of the status quo of power system infrastructures as well as the near- and long-term planning processes for transmission and generation assets in North Africa.

- Hourly representation of the countries' electricity load in order to explore interactions with the intermittent RES-E generation and the dispatching of conventional power plants.

- The ability to mirror different levels of regional cooperation.

Geographically, this study focuses on the five North African countries that are represented as distinct model regions. Additionally, in order to reflect electricity exchanges with adjacent 
electricity systems, Europe and eastern Mediterranean countries are included, but in a less refined manner as aggregated satellite regions (see Figure 1).

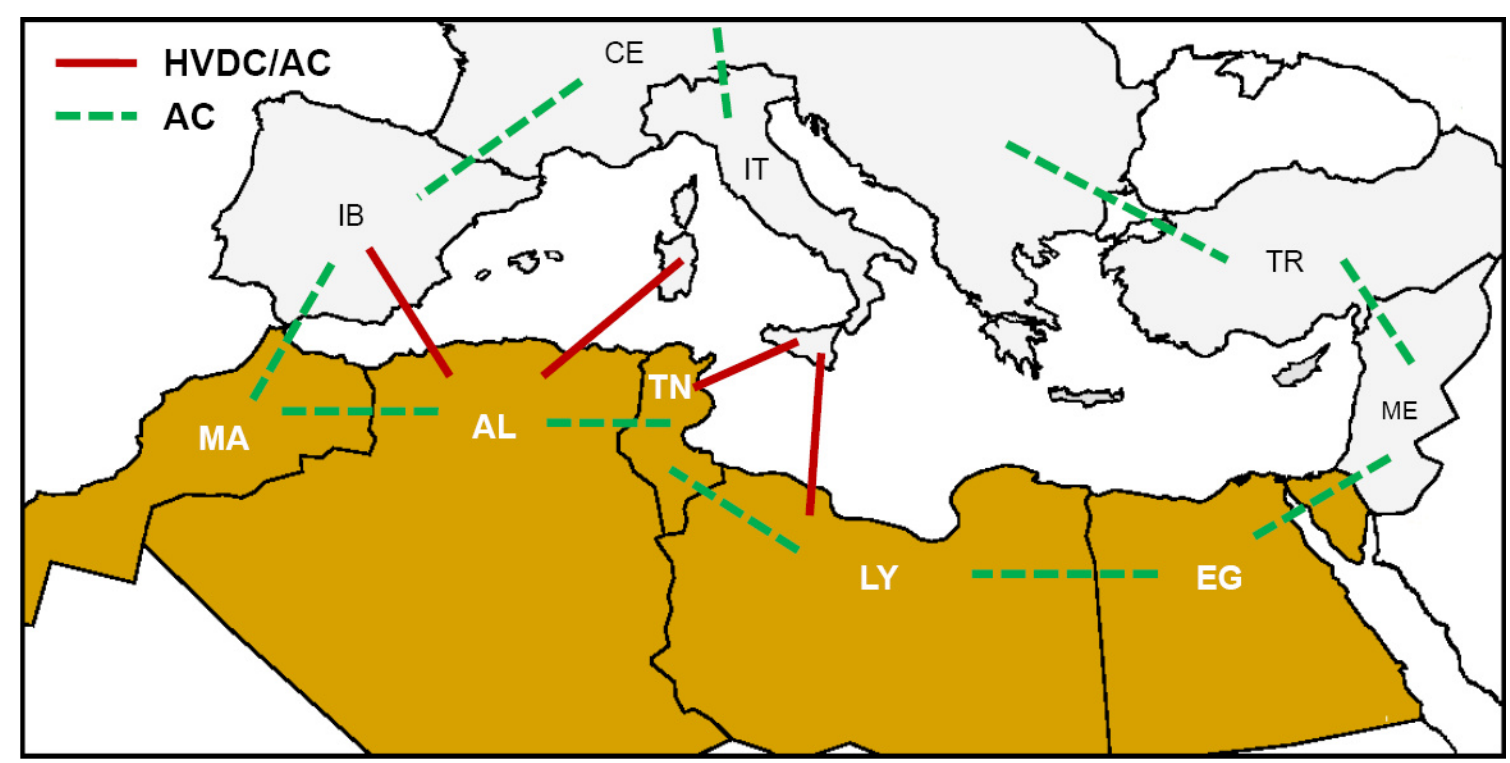

Figure 1. Model regions: Morocco (MA), Algeria (AL), Tunisia (TN), Libya (LY) and Egypt (EG). Satellite regions: Iberian Peninsula (IB), ENTSO-E Continental Europe (CE), Italy (IT), Turkey (TR) and East Mediterranean countries (ME).

\section{Model description}

Analyzing the transformation of interconnected power systems typically is performed with linear models that combine the long-term optimization of investment planning with the shortterm dynamics of system operation on a seasonal, daily and often hourly basis. The methodology in this study likewise follows this approach, as it is done by a number of similar dispatch and investment models, for instance applied by EWI/Energynautics (2011), Haller et al. (2012), or Bartels (2009). For reasons of space, and because the approach has been sufficiently described in the literature, the following paragraphs only sketch the most important model functions and particularities pertinent to the analysis of North African power markets.

\subsection{Objective function and decision variables}

The objective function, the central element of any linear program, is the total discounted system cost, the sum of investment annuities of generation capacity $\left(I N V_{y}\right)$, the costs of operation and maintenance, $\left(O M_{y}\right)$, other variable costs, $\left(V A R_{y}\right)$, and fuel costs $\left(F U E L_{y}\right)$, as 
well as the investment associated with the set-up of net transfer capacity (NTC) for power transmission $\left(I N V_{-} N T C_{y}\right)$.

$$
T O T A L=\sum_{y} d i s C_{y} \cdot\left(I N V_{y}+O M_{y}+V A R_{y}+F U E L_{y}+I N V_{-} N T C_{y}\right)
$$

The different cost constituents are aggregated into 5-year periods $(y=2010,2015,2020$, etc.) and discounted with an overall real discount rate of 5\% to a net present value in 2010 $\left(€^{2010}\right)$. The model seeks to minimize the total costs TOTAL by finding optimized values for the following decision variables:

- Investments in generation capacity $C A P_{i, r, y}$ (in MW) of each technology type $i=c o a l$, gas, csp, wind,... in the period $y$ and region $r$.

- The expansion of installed transmission capacity $N T C_{r, r^{*}, y}$ (in $\mathrm{MW}$ ) between two model regions $r$ and $r^{*}$.

- The hourly (h) electric energy generation $G E N_{i, r, y, d, h}$ (in MWh) for each representative day $(d)$ in the period $y$.

- The hourly electric power transmission $T R A N S_{r, r^{*}, y, d, h}$ (in $\mathrm{MW}$ ) from region $r$ to region $r^{*}$.

The indices associated with the variables characterize the main regional, temporal and technological features of the model and are listed in Table 1.

Table 1. Model definition

\begin{tabular}{lll}
\hline Index & Definition & Denotation \\
i & generation technology & $\begin{array}{l}\text { coal, lignite, nuclear, gas_cc, gas_oc, gas_st, oil, pv, csp, } \\
\text { wind_onsh, wind_offsh, biomass, hydro, hydro_pump. }\end{array}$ \\
r, r & model region & MA, AL, TN, IB, IT, CE, TR, ME, EG, LY \\
y & model period & $2010,2015, \ldots$ \\
d & representative day & $1, \ldots, 24$ \\
h & hour & $1, \ldots, 24$ \\
\hline
\end{tabular}




\subsection{Energy balance constraint}

The energy balance constraint ensures that electricity supply meets the electricity demand in any region at any given moment in time.

$$
\begin{array}{r}
\operatorname{load}_{r, y, d, h}+\sum_{r^{*}} \operatorname{TRANS}_{r, r^{*}, y, d, h}+\operatorname{HYD}_{-} P U M P_{r, y, d, h} \\
=\sum_{\text {tech }} G E N_{i, y, d, h}+\sum_{r^{*}}\left(1-\operatorname{loss}_{r, r^{*}, y}\right) \cdot \operatorname{TRANS}_{r^{*}, r, y, d, h}
\end{array}
$$

The left side of the equation, the total regional electricity demand, is the sum of the hourly electricity load $\left(\operatorname{load}_{r, y, d, h}\right)$, the energy transmitted from region $r$ to neighboring regions $r^{*}$ $\left(T R A N S_{r, r^{*}, y, d, h}\right)$, and the electricity used for pumping into hydro storage systems $\left(H Y D_{-} P U M P_{r, y, d, h}\right)$. Electricity transmission between two regions must not exceed the net transfer capacity $\left(T R A N S_{r, r^{*}, y, d, h} \leq N T C_{r, r^{*}, y}\right)$.

\subsection{Operational constraints for power plants}

Modeling the operation of power plants requires a large set of constraints, describing the technical particularities of each power generation technology. For thermal power plants (fossil and nuclear power, as well as biomass-driven units), the dispatch properties are mainly ruled by the limitations of the steam or gas turbine: efficiencies, ramp-up behavior and part-load conditions. Hydroelectric power plants have only limited significance for North Africa, as only Egypt and Morocco exhibit noteworthy capacities. These are simulated by taking into account seasonal water inflows and the reservoir size of the water storage in the case of hydro dams or pumped storage facilities. Renewable power generation technologies like wind and photovoltaic (PV) plants are bound to the intermittent availability of irradiation and wind speed. The model reflects this by deterministic output patterns of standard wind turbines and PV plants that were calculated on basis of hourly historic meteorological data of representative sites in each region. Unlike wind and PV, concentrated solar power plants (CSP) can feature storage systems to transform (direct) solar irradiance into dispatchable electricity. For this study, we assumed a dry-cooled parabolic trough power plant, with 6 
hours thermal storage and a solar multiple of 2. The simulation of storage-based CSP plant operation within linear models is described in Brand et al. (2012).

\subsection{Constraints of supply security and interregional cooperation}

Technical and security requirements, as well as aspects of interregional cooperation are mirrored by further equations. The peak load constraint ensures that in each period $(y)$ sufficient generation capacity is available to meet the maximum power demand. This criterion is of high importance for the North African countries, where the peak loads set new records every year. The parameter peakload $($ in MW, including a security margin) represents the expected maximum load in each period $y$, corresponding to forecasts published by national TSOs or electricity regulators. In interconnected power systems, the capacity assigned to cover the peak load can be differentiated as follows (see Al Khal et al., 2006):

$$
\begin{gathered}
\text { peakload }_{r, y} \leq \\
\sum_{i} C A P_{i, r, y} \cdot a v_{i, r, y} \cdot \text { cap_credit }_{i, r, y}+\sum_{r^{*}}\left(1-\operatorname{loss}_{r^{*}, r, y}\right) \cdot C A P_{-} S_{r^{*}, r, y}-\sum_{r^{*}} C A P_{-} S_{r, r^{*}, y}
\end{gathered}
$$

First, it can be provided domestically, by the sum of all installed power generation technologies $C A P_{i, r, y}$ in the model region $r$. The parameters $a v_{t e c h, y, d}$ and cap_credit tech,y $_{\text {. }}$ are percentage values referring to the typical plant availability and the capacity credit ${ }^{3}$ of each technology. A second contributor to peak load coverage could be foreign capacity, if one region $r^{*}$ guarantees another region $r$ apart of its generation capacity for the event of peak loads. This 'shared' capacity, $C A P_{-} S_{r^{*}, r, y}$, is reduced by a loss factor $\left(1-\operatorname{loss}_{r^{*}, r, y}\right)$ to consider power drops along the transnational interconnector. Conversely, all capacity that region $r$ reserves for other regions, $C A P_{-} S_{r^{*}, r, y}$, needs to be subtracted as it is not available for domestic peak coverage. A further boundary condition $\left(C A P_{-} S_{r^{*}, r, y} \leq N T C_{r, r^{*}, y}\right)$ constrains the shared capacity to not exceed the interconnector's NTC value.

3 In this study, the capacity credit is understood as the capability of a specific generation technology $i$, to provide firm capacity to the power system. The capacity credit of conventional power plants is always $100 \%$, while for intermittent renewable technologies it is significantly lower. 
The technical possibility to counter peak loads with foreign generation capacity does not necessarily mean that all countries actually desire this option. Especially in North Africa, one could imagine political misgivings concerning dependency on other countries' generation assets. Following the approach by Al Khal et al. (2006) an additional equation was introduced to define the level of accepted reliance of a country from external capacity:

$$
\sum_{r^{*}}\left(1-\operatorname{losS}_{r^{*}, r, y}\right) \cdot \text { CAP_S }_{r^{*}, r, y} \leq\left(1-\text { autonomy }_{r, y}\right) \cdot \text { peakload }_{r, y}
$$

By setting an individual autonomy factor $\left(\right.$ autonom $y_{r, y}$ ), each region can decide the extent to which it would tolerate other regions' capacity to cover its peak loads. If $100 \%$ autonomy is chosen $\left(\right.$ autonomy $\left.y_{r, y}=1\right)$, then $C A P \_S_{r^{*}, r, y}$ becomes zero, meaning that the region wants to secure its peak load entirely with own capacity. Different autonomy factors thus allow for simulation of different regional cooperation scenarios regarding the joint utilization of generation capacity.

A second dimension of cooperation concerns electricity imports. Here, the key criteria is not capacity, but energy. In the model, the level of energy independency is defined by the share of the annual electric energy demand (in GWh) that must be generated domestically:

$$
\text { annual_demand }_{y, r} \cdot \text { self_supply } y_{r, y} \leq \sum_{i, d, h} G E N_{i, y, d, h}
$$

With the parameter self_supply $y_{r, y}$, the allowed level of import dependency can be adjusted: setting self_supply $y_{r, y}=100 \%$ is equivalent to a situation where a region is constrained to fully satisfy its demand by own generation; lower values of self_supply ${ }_{r, y}$ would represent a higher tolerance of electricity imports. Limiting import dependency can be considered a strategy for those countries whose governments protect the local power generation industries and support the use of domestic energy resources. 


\section{Assumptions and scenarios}

\subsection{Demand and load}

Demand and load projections in this study rest on historic electricity data for the year 2010 that were carried forward until 2030 on the basis of annual growth rate assumptions made by OME, 2011 ("conservative scenario", assuming continuation of past demand trends into the future). Table 2 lists the annual demand (annual_demand ${ }_{y, r}$ ) of the North African model regions, as well as the corresponding forecasts for the maximum peak load (peakload $r, y$ ) for the years 2010, 2020, and 2030 .

Table 2. Assumptions for annual demand and peak load developments.

\begin{tabular}{|c|c|c|c|}
\hline \multirow[t]{2}{*}{ Region } & \multicolumn{3}{|c|}{ Annual demand (TWh) / Peak load (MW) } \\
\hline & 2010 & 2020 & 2030 \\
\hline Morocco (MA) & $27.5 / 4790$ & $46.1 / 8030$ & $64.0 / 11140$ \\
\hline Algeria (AL) & $45.2 / 7720$ & $75.8 / 12940$ & $105.1 / 17950$ \\
\hline Tunisia (TN) & $14.9 / 3010$ & $25.0 / 5050$ & $34.7 / 7000$ \\
\hline Libya (LY) & $30.4 / 5280$ & $51.0 / 8850$ & $70.7 / 12280$ \\
\hline Egypt (EG) & $133.3 / 22750$ & $223.4 / 38130$ & $310.0 / 52900$ \\
\hline
\end{tabular}

For Turkey and the East Mediterranean model region, the demand scenarios likewise refer to OME's growth forecasts, while the corresponding projections for the EU satellite regions are based on the "EU Reference scenario" data in Capros et al. (2009). The hourly electric load was calculated on basis of historical time series provided by TSOs or national electric utilities $^{4}$. To the extent it was possible, data was used from the basis year 2010, of which 24 representative days $(d)$ - of each month one working day and one weekend day - were selected. These load patterns were normalized and scaled up with the annual demand in order to obtain the hourly load (load $r, y, d, h)$ for future periods until 2030.

\subsection{Generation}

The following generation technologies are covered by the model: nuclear power, lignite and hard coal, gas-powered steam plants (Gas ST), combined cycle (Gas CC) gas and open cycle For the European model regions, 2010 data from ENTSO-E was used. 
(Gas OC) gas turbines, liquid fuel-fired power plants (Oil), hydropower (including pumped storage), biomass, wind (onshore and offshore), photovoltaic (PV), and CSP. The most important technical and financial model parameters are listed in Table 3. Most parameters were taken from a previous study on the Tunisian power system (GIZ, 2011), which was considered reasonable for the other North African countries, as well.

Table 3. Power plant parameters assumptions

\begin{tabular}{|c|c|c|c|c|c|c|c|c|}
\hline & $\begin{array}{c}\text { Invest. }(€ / \mathbf{k W}) \\
2010 / 2020 / 2030\end{array}$ & $\begin{array}{c}\text { Fix. } \\
\text { O\&M } \\
(€ / \mathbf{k W a})\end{array}$ & $\begin{array}{c}\text { Var. } \\
\text { O\&M }(€ / \\
\left.\operatorname{MWh}_{\mathrm{el}}\right)\end{array}$ & $\begin{array}{c}\text { Tech. } \\
\text { avail. } \\
(\%)\end{array}$ & $\begin{array}{c}\text { Effici } \\
\text { ency( } \\
\%)\end{array}$ & $\begin{array}{c}\text { Cap. } \\
\text { credit } \\
(\%)\end{array}$ & $\begin{array}{l}\text { Min. } \\
\text { load } \\
(\%)\end{array}$ & $\begin{array}{c}\mathrm{CO}_{2} \\
\text { emission } \\
\left(\mathrm{tCO}_{2} /\right. \\
\left.\mathrm{MWh}_{\text {th }}\right)\end{array}$ \\
\hline Coal & 2130 & 22.8 & 3.1 & 85 & 40 & 100 & 50 & 0.34 \\
\hline Lignite & 1800 & 40.0 & 1.0 & 85 & 42 & 100 & 60 & 0.41 \\
\hline Nuclear & 4170 & 53.2 & 0.4 & 85 & 33 & 100 & 65 & - \\
\hline Gas OC & 675 & 8.2 & 2.5 & 85 & 34 & 100 & 20 & 0.20 \\
\hline Gas ST & 900 & 15.0 & 1.6 & 85 & 39 & 100 & 45 & 0.20 \\
\hline Gas CC & 900 & 9.7 & 1.6 & 85 & 53 & 100 & 40 & 0.20 \\
\hline Oil & 775 & 8.2 & 2.5 & 85 & 32 & 100 & 20 & 0.28 \\
\hline Biomass & 1500 & 60.0 & 2.8 & 85 & 32 & 100 & 20 & - \\
\hline Hydro & 2000 & 20.0 & 0.0 & 99 & - & 100 & - & - \\
\hline Wind onsh. & $1150 / 980 / 930$ & 40.0 & 0.0 & 97 & - & 5 & - & - \\
\hline Wind offsh. & 2,000 & 100.0 & 0.0 & 95 & - & 8 & - & - \\
\hline PV & $2500 / 1380 / 1000$ & 20.0 & 0.0 & 99 & - & $0-5^{*}$ & - & - \\
\hline CSP & $6090 / 4200 / 3400$ & 53.8 & 0.0 & 96 & - & 90 & 20 & - \\
\hline
\end{tabular}

* the capacity credit for PV is considered $0 \%$ for European countries, $5 \%$ for MENA due to more constant irradiation and a trend to midday load peaks.

To reflect region-specific particularities, the model included several exogenous restrictions to the possible expansion of generation technologies. For political and technical reasons, the installation of nuclear power, lignite, biomass and offshore wind technologies was precluded in North Africa until 2030. Coal steam power plants can only be built in Morocco -where the technology is already in use - and Tunisia, which is considering a coal diversification strategy starting in 2020 (GIZ, 2011). The 2010 power plant stock of all North African countries is summarized in Table 4; data was taken from annual reports of North African utilities and AUPTDE publications. The power plant inventories of the European satellite regions are based on ENTSO-E (2011), TEİAŞ (2012) for Turkey and PWMSP (2011) for the East Mediterranean model region. 
Table 4. North African power plant inventory by the end of 2010.

\begin{tabular}{cccccc}
\hline & \multicolumn{5}{c}{ Installed generation capacities (MW) in 2010 } \\
\cline { 2 - 6 } & Morocco & Algeria & Tunisia & Libya & Egypt \\
\hline Coal & 1785 & - & - & - & - \\
Gas OC & 915 & 6565 & 1512 & 2019 & 2841 \\
Gas ST & - & 2487 & 1080 & - & 10334 \\
Gas CC & 850 & 2042 & 784 & 2430 & 7137 \\
Oil & 803 & 245 & - & 2000 & 1124 \\
Hydro & 1770 & 228 & 66 & - & 2800 \\
Wind & 221 & - & 54 & - & 490 \\
PV & - & - & - & - & - \\
CSP & - & - & - & - & - \\
\hline
\end{tabular}

\subsection{Renewable and fossil resources}

\subsubsection{Meteorological data}

The electricity generation of solar power plants and wind farms is ruled by irradiation conditions and wind speed. The deterministic operation patterns needed for CSP and PV modeling were calculated with the System Advisor Model (NREL, 2012) on basis of global horizontal irradiation (GHI) and direct normal irradiance (DNI) time series at representative sites in the different model regions. The time series -provided by Helioclim (2012) - were selected such that they correspond to the 24 calendar dates of the electricity load in 2010 . Wind power production, likewise matching to these days, was calculated with the MINT software (Sander+Partner, 2012) on basis of MERRA wind speed time series (MERRA, 2012). For hydropower generation, historic seasonal water inflow profiles were used. It must be premised that the use of deterministic meteorological data (wind and solar radiation), represents a simplification. Therefore, for future studies, it is desirable to likewise consider the stochasticity of intermittent generation in the simulations. A further aspect worthy to be taken into account - especially when it comes to long-term electricity system forecasts - is climate change and its potential impact on the availability of the renewable resources in the MENA region over the coming decades. 


\subsubsection{Fuel costs}

Table 5 displays the price scenario used for this study. Prices are expressed in $€^{2010} / \mathrm{MWh}_{\text {th }}$ (lower heating value) and represent each fuel's opportunity cost. It has to be noted that in North Africa, the assumption of uniform opportunity costs can be undermined by the fact that gas-producing countries, especially those with intertwined gas- and electricity state monopolies, often tend to supply the power system with gas at much lower costs. The associated distortions that such indirect subsidies could have on the model results are analyzed in a sensitivity analysis in section 5.4.1.

Table 5. Fuel price pathways. Source: IEA, 2011 (current policies scenario), own assumptions.

\begin{tabular}{lcccc}
\hline & \multicolumn{3}{c}{ Fuel costs $\left(\boldsymbol{€} / \mathbf{M W h} \mathbf{h}_{\mathbf{t h}}\right)$} \\
\hline & $\mathbf{2 0 1 0}$ & $\mathbf{2 0 2 0}$ & $\mathbf{2 0 3 0}$ \\
\cline { 2 - 3 } Coal & 1.7 & 2.1 & 2.3 \\
Oil & 10.2 & 11.2 & 12.0 \\
Lignite & 36.2 & 54.7 & 62.3 \\
Natural Gas & 1.5 & 1.5 & 1.5 \\
Biomass & 19.3 & 28.3 & 32.4 \\
\hline
\end{tabular}

\subsubsection{Carbon emissions}

Threatened by water scarcity and desertification, and with a densely populated coastal zone exposed to sea-level rise, the North African region is particularly vulnerable to climate change (AfdB, 2012). Although all North African countries have signed and ratified the Kyoto Protocol and are occasionally also involved in Clean Development Mechanism (CDM) projects within this framework, the decarbonization of power systems currently is only a minor motivation for the regional decision makers; energy security, industrial development and job creation, are seen as much more important drivers for RES-E projects in North Africa. Therefore, it remains uncertain whether the region will soon get involved in larger emission trading schemes, such as practiced in the EU. Nevertheless, the question of an equitable accounting of $\mathrm{CO}_{2}$ emissions will be raised in North Africa as well if the power systems become embedded in liberalized, integrated electricity markets with strong interconnections with the EU. In this case, in order to provide for equal competition, and to prevent carbon leakage through electricity transmission (e.g. the setup of carbon-intensive generation 
technologies in the South), it can be expected that a level playing field with consistent costs for $\mathrm{CO}_{2}$ emissions will be established. In this model, therefore, a scenario of homogenous $\mathrm{CO}_{2}$ costs was applied, amounting to $15 € / \mathrm{tCO}_{2}$ in 2010 , with a stepwise increase to $30 € / \mathrm{tCO}_{2}$ until 2030 (IEA, 2011, current policies scenario). A sensitivity analysis was carried out in section 5.4.2 to analyze the case of disparate $\mathrm{CO}_{2}$ costs between different countries.

\subsection{Transmission}

In the model, upgrades of NTC capacity $\left(N T C_{r, r^{*}, y}\right)$ can only take place along predefined transmission corridors (see Figure 1) referring to technically and economically reasonable Mediterranean interconnection options until 2030 (see MED-EMIP, 2010). It is assumed that no HVDC network technology will be utilized for terrestrial applications until 2030. Therefore, overland transmission is realized strictly with $\mathrm{AC}$ technology. Interconnectors crossing the Mediterranean Sea, however, involve the utilization of HVDC cables, connecting $\mathrm{DC} / \mathrm{AC}$ converter stations at the two sides of the shore ${ }^{5}$. Undersea cable distances and landing points are taken from MED-EMIP (2010), while the length of the overland lines is estimated as distance between centers of high population density. The technical and cost parameters associated with the transmission assets are summarized in Table 6.

Table 6. Transmission technology parameters. Sources: Realisegrid (2010), MED-EMIP (2010). The investment cost assumptions include a security margin of $100 \%$ for AC and 20\% for HVDC (Dii, 2012).

\begin{tabular}{lcccc}
\hline & \multicolumn{2}{c}{ Transmission lines } & \multicolumn{2}{c}{ Converter terminal pair } \\
\hline & $\begin{array}{c}\text { Inv. costs } \\
\left(€ / \mathbf{M W}_{\mathbf{N T C}} \cdot \mathbf{k m}\right)\end{array}$ & $\begin{array}{c}\text { Line losses } \\
(\% / \mathbf{1 0 0 0} \mathbf{~ k m})\end{array}$ & $\begin{array}{c}\text { Inv. costs } \\
\left(\boldsymbol{(} / \mathbf{k W} \mathbf{N T C}_{\mathbf{N}}\right)\end{array}$ & $\begin{array}{c}\text { Converter losses } \\
(\% / \mathbf{1 0 0 0} \mathbf{~ k m})\end{array}$ \\
\cline { 2 - 5 } AC overland (400kV) & 800 & 10.0 & - & - \\
HVDC submarine $(\mathbf{4 0 0} \mathbf{~ k V )}$ & 1200 & 5.0 & 150 & 1.4 \\
\hline
\end{tabular}

The existing NTC values in the base year 2010 are taken from MED-EMIP (2010), while data published by ENTSO-E (2012), was used for interconnectors between and within the European satellite regions. The model likewise considers endogenous NTC additions until 2015, if they are part of fixed planning programs, for example outlined in TYNDP (2012).

5 Exceptions are Morocco-Spain connection, realized in AC, and the Libya-Tunisia corridor, for which an HVDC back-to-back converter station is foreseen to asynchronously link the two electricity systems. The corridors to Italy via the islands Sardinia and Sicily include additional AC and HVDC connections to mainland Italy, which are for clarity purposes not shown in Figure 1. 


\subsection{Renewable electricity goals}

One particular objective of this study is to analyze the impacts of RES-E penetration on interconnected regional power markets in North Africa. All five countries have drafted roadmaps for RES-E deployment (see the synopsis in Table 7). As these goals have been pronounced by official sources - mostly ministries or government agencies - they are considered as the baseline scenario for RES-E deployment in this study. Nevertheless, it is worth noting that North African RES-E targets underwent several modifications in the past, and it is not unlikely that they might become subject to further revision if, for instance, political or economic frameworks change.

Table 7. North African RES-E goals for wind, PV and CSP capacity

\begin{tabular}{|c|c|c|c|c|}
\hline Region & Wind (MW) & CSP (MW) & PV (MW) & Source \\
\hline & $2010 / 2020 / 2030$ & $2010 / 2020 / 2030$ & $2010 / 2020 / 2030$ & \\
\hline MA & $221 / 2000 / 4000^{*}$ & $0 / 1000^{* *} / 2000^{*}$ & $0 / 1000^{* *} / 2000^{*}$ & ONE, 2008, Masen,2012 \\
\hline $\mathbf{A L}$ & $0 / 270 / 1750$ & $0 / 1500 / 7725$ & $0 / 830 / 2800$ & $\begin{array}{l}\text { MEM, 2011, PWMSP, } \\
2012\end{array}$ \\
\hline $\mathbf{T N}$ & $54 / 500 / 1520$ & $0 / 200 / 600$ & $0 / 800 / 1930$ & $\begin{array}{l}\text { GIZ, 2011; African } \\
\text { Manager, } 2012 .\end{array}$ \\
\hline $\mathbf{L Y}$ & $0 / 1500 / 2500^{*}$ & $0 / 800 / 1600^{*}$ & $0 / 150 / 850^{*}$ & REAOL, 2012 \\
\hline EG & $490 / 7200 / 14800^{*}$ & $0 / 800^{* *} / 2550^{*}$ & $0 / 800^{* *} / 2550^{*}$ & $\begin{array}{l}\text { NREA, 2012; Younis, } \\
2012\end{array}$ \\
\hline
\end{tabular}

*) extrapolated ${ }^{* *}$ ) solar capacity goals split into 50\% PV and 50\% CSP

The model likewise incorporates RES-E targets of the satellite regions: for the East Mediterranean region, these assumptions are based on PWMSP (2012); for European countries, the model relies on EU's National Renewable Energy Action Plans (NREAP) based on data from ECN (2011). Trends were extrapolated until 2030.

\section{Results}

\subsection{Baseline scenario}

The first scenario to be examined is a baseline scenario in which North African countries fulfill their RES-E capacity goals, but remain reluctant regarding upgrades of transnational interconnectors. Therefore, no endogenous transmission asset additions are considered in the 
baseline scenario. Moreover, it is assumed that all regions exhibit aversion to power system cooperation: the model parameters self_supply $y_{r, y}$ and autonomy $y_{r, y}$ stay at their current, high levels ${ }^{6}$. Figure 2 shows the simulated transmission capacities and power exchanges under these conditions for 2030. As expected, power transfers remain low, in particular in the eastern part of North Africa (Libya and Egypt), which continues to be disconnected from the western system (Morocco, Algeria, Tunisia) because the baseline scenario excludes the construction of a Libya-Tunisia interconnection. Electricity exchanges between North Africa and Europe only take place on the Spain-Morocco interconnector, with a net power flow of $240 \mathrm{GWh}$ in the North-South direction in 2030. This is a significant decrease compared to 2010, for which the model calculated $5400 \mathrm{GWh}$ of Moroccan imports from Spain ${ }^{7}$. The finding that Morocco can reduce its imports until 2030 can be attributed to lower electricity generation costs due to an increased domestic construction of RES-E and coal power plants, which render -in the long run- imports less attractive.
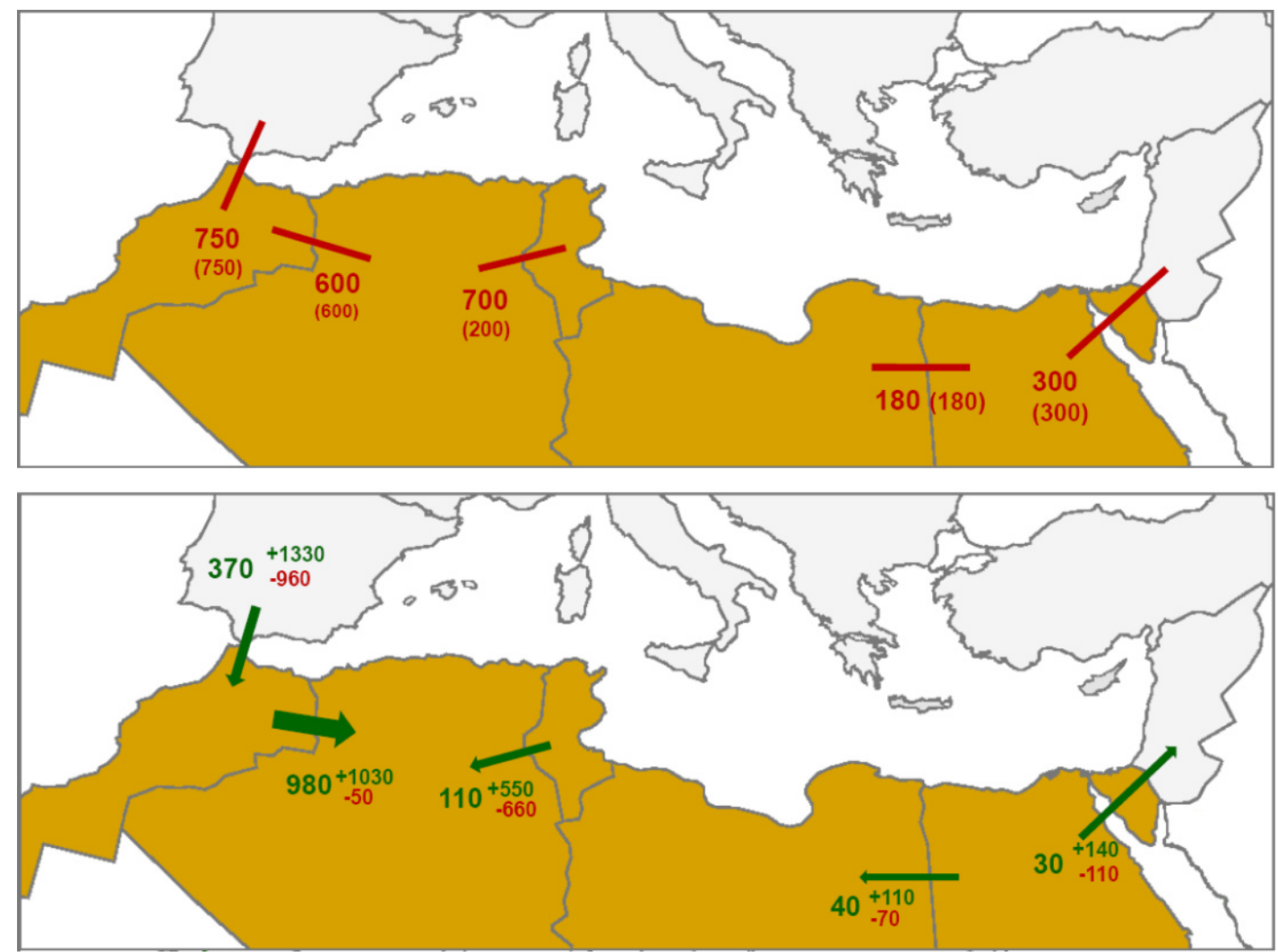

Figure 2. Baseline scenario. Top: 2030 installed NTC capacities in MW (values in brackets: 2010 capacities). Bottom: Annual net energy flows in GWh in 2030 ( + - symbols indicate the gross exchanges between the model regions)

$6 \quad$ For both parameters an average value of $97 \%$ is assumed, except for Morocco, where a self-supply rate of $83 \%$ reflects high electricity imports from Spain amounting to $17 \%$ of the national demand in 2010. According to the utility's reports, the actual imports amounted to $3900 \mathrm{GWh}$ in 2010 and $4500 \mathrm{GWh}$ in 2011 (ONE, 2011). 


\subsection{Power system cooperation scenarios}

\subsubsection{Economic benefits of cooperation}

This section analyzes the extent to which transnational electricity interconnectors would be constructed if the North African countries were to fulfill their individual RES-E goals but accept higher reliance on neighboring generation capacity and electricity imports. As described in chapter 3.4., one can distinguish between two dimensions of reliance: first, the tolerance of electricity imports; and second, the willingness to jointly share generation capacity for peak-load coverage. In the model, both dimensions were simulated by adjusting the parameters self_supply ${ }_{r, y}$ and autonomy $y_{r, y}$, in 25\% steps. Setting self_supply $y_{r, y}=75 \%$ and autonomy $y_{r, y}=100 \%$ corresponds to the case where a country is willing to accept up to $25 \%$ of foreign electricity imports, but prefers full independency when it comes to safeguarding its power system against peak load events. Vice-versa, high self-supply requirements (self_supply ${ }_{r, y} \approx 100 \%$ ) are tantamount to electricity import aversion, for example, if governments pursue 'mercantilist' strategies by giving priority to domestic over foreign electricity generation.

Table 8. Cost benefits of cooperation: Cumulated cost savings of all North African countries until 2030 compared to the baseline scenario.

\begin{tabular}{|c|c|c|c|}
\hline & \multicolumn{3}{|c|}{ Cooperation scenarios } \\
\hline & $\begin{array}{l}\text { "Import reliance / } \\
\text { capacity autonomy" }\end{array}$ & $\begin{array}{l}\text { "Import aversion / } \\
\text { capacity reliance" }\end{array}$ & $\begin{array}{l}\text { "Mixed capacity and } \\
\text { import reliance" }\end{array}$ \\
\hline & $\begin{array}{l}\text { (autonomy } \approx 100 \%, \\
\text { self_supply }=75 \% \text { ) }\end{array}$ & $\begin{array}{c}\text { (autonomy }=75 \% \\
\text { self_supply } \approx 100 \% \text { ) }\end{array}$ & $\begin{array}{c}\text { (autonomy }=75 \% \\
\text { self_supply }=75 \%)\end{array}$ \\
\hline $\begin{array}{l}\text { Savings in the generation system } \\
\left(€^{2010} \text { million }\right)\end{array}$ & 2209 & 1282 & 3942 \\
\hline $\begin{array}{l}\text { Surplus costs for the transmission } \\
\text { system }\left(€^{2010} \text { million }\right)\end{array}$ & -500 & -306 & -554 \\
\hline Total benefit ( $€^{2010}$ million) & 1709 & 976 & 3388 \\
\hline
\end{tabular}

Table 8 displays the discounted and aggregated cost savings between the baseline scenario and three different cooperation scenarios until 2030. It can be observed that considerable economic gains for the entire generation system (in terms of fuel savings, and avoided capacity additions) can be achieved with increased cooperation. These gains largely overcompensate for the surplus costs of the transmission capacity required for the different 
power systems - leaving an overall net benefit in all cooperation scenarios. It reaches a maximum of around $€ 3.4$ billion $^{8}$ in the "mixed capacity and import reliance scenario," in which the model regions simultaneously cooperate on interregional electricity exchange and peak capacity sharing (self_supply $y_{r, y}$ and autonomy $y_{r, y}$ both set at 75\%). Additional model runs show that with a further increase of interregional reliance (by lowering the parameters to $50 \%$ or more) no additional benefits could be achieved.

\subsubsection{Interconnector capacities and power transfers}

Looking in more detail at the interconnector topology and the physical exchanges of the lastmentioned cooperation scenario reveals that interconnector upgrades and electricity exchanges preferentially take place among the Maghreb countries and their immediately adjacent European neighbors (see Figure 3):
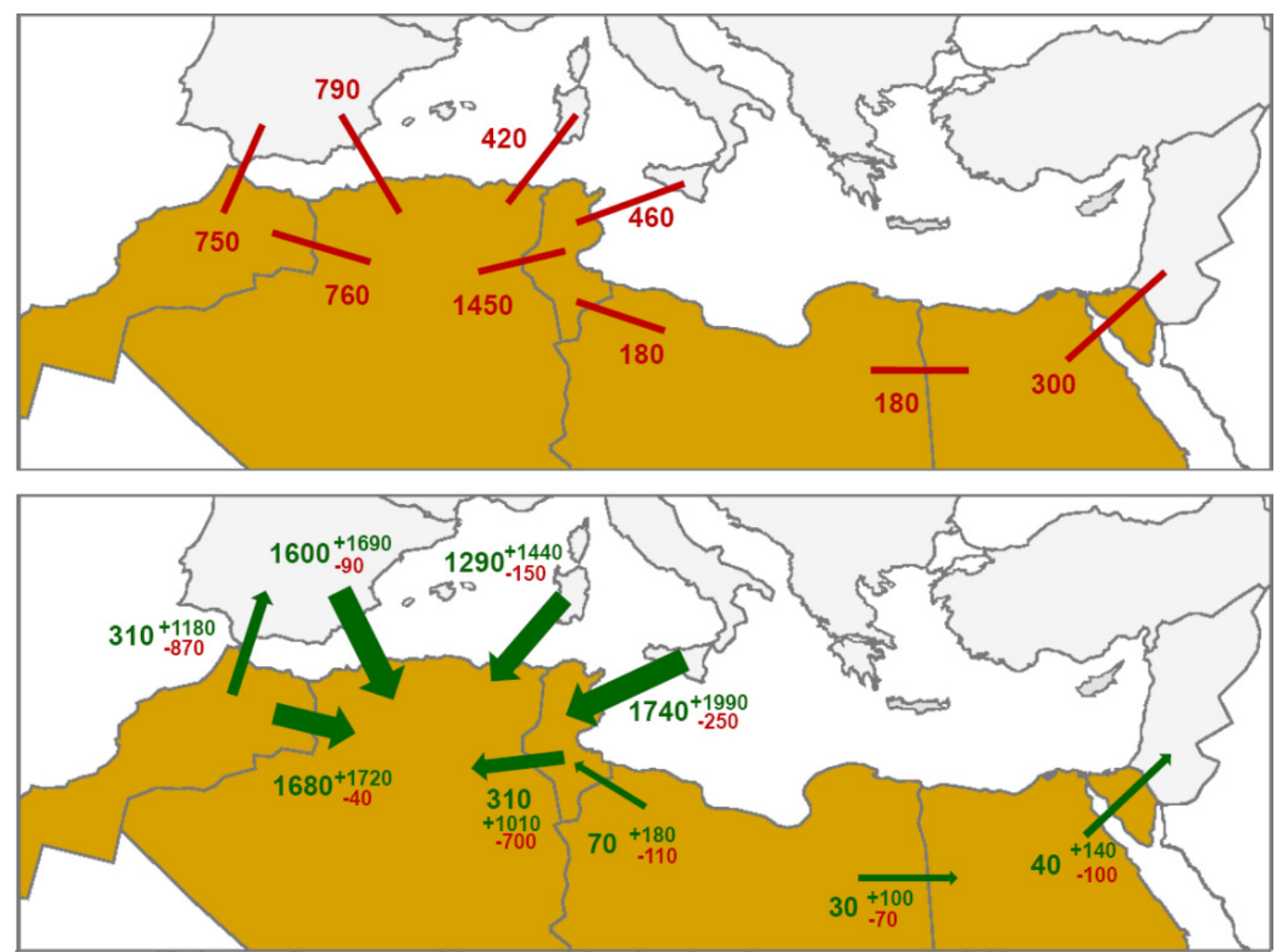

Figure 3. NTC capacities (top, in MW) and net annual energy transfers (bottom, in GWh) in the "mixed capacity and import reliance" scenario.

8 This value represents approximately 1\% of the total costs of the North African power system until 2030. 
Power transmission in Libya and Egypt remain moderate, which can be attributed to prohibitive high investment costs and energy losses of AC transmission crossing these large territorial states ${ }^{9}$. A further finding is that Europe remains a net electric energy exporter in 2030, transmitting around 4.6 TWh to North Africa via three new power lines across the Mediterranean Sea. Only Morocco exports a minor amount of power - 0.3 TWh to Spain. Electricity generation cost differentials between the two continents explain why North Africa obviously still prefers imports from Europe: The European satellite regions operate a comparatively cheaper conventional power plant fleet (coal, nuclear power), which, together with the expected expansion of renewable power according to the NREAP goals, will -for the coming two decades- keep the (marginal) electricity generation costs in Europe still more competitive than in North Africa. The resulting North-South electricity transfers are further eased by the situation that demand in Europe stagnates while it increases in North Africa.

It is likewise remarkable that Algeria becomes a major import destination in 2030, receiving net electricity transfers from all adjacent model regions. This surprising result (typically, Algeria is known as an energy-exporting nation) can be explained by the price differentials of electricity generation between different model regions: Algeria's conventional power generation system is almost entirely fueled by natural gas, and the dominance of this expensive primary source keeps the Algerian generation costs high in comparison to other regions - despite the construction of an important number of solar power plants in the country by 2030 . It is noted that this observation rests on the underlying assumption that opportunity fuel costs are being applied in the model. In practice, however, this economic rationale is often ignored: especially in oil- and gas-exporting countries, national electricity utilities receive fuels at significantly lower prices than the opportunity costs, or even enjoy fuel subsidies (for a discussion in which way such a behavior distorts the model results, see section 5.4.1).

\subsubsection{Capacities, generation and power plant dispatch}

The power dispatch behavior in Figure 4 shows an example of the generation systems' operation and power exchanges between the five North African model regions on a weekday in summer (July).

\footnotetext{
9 As a reminder,the present study assumes that no HVDC grid technology would be used for overland interconnection between North African model regions until 2030.
} 

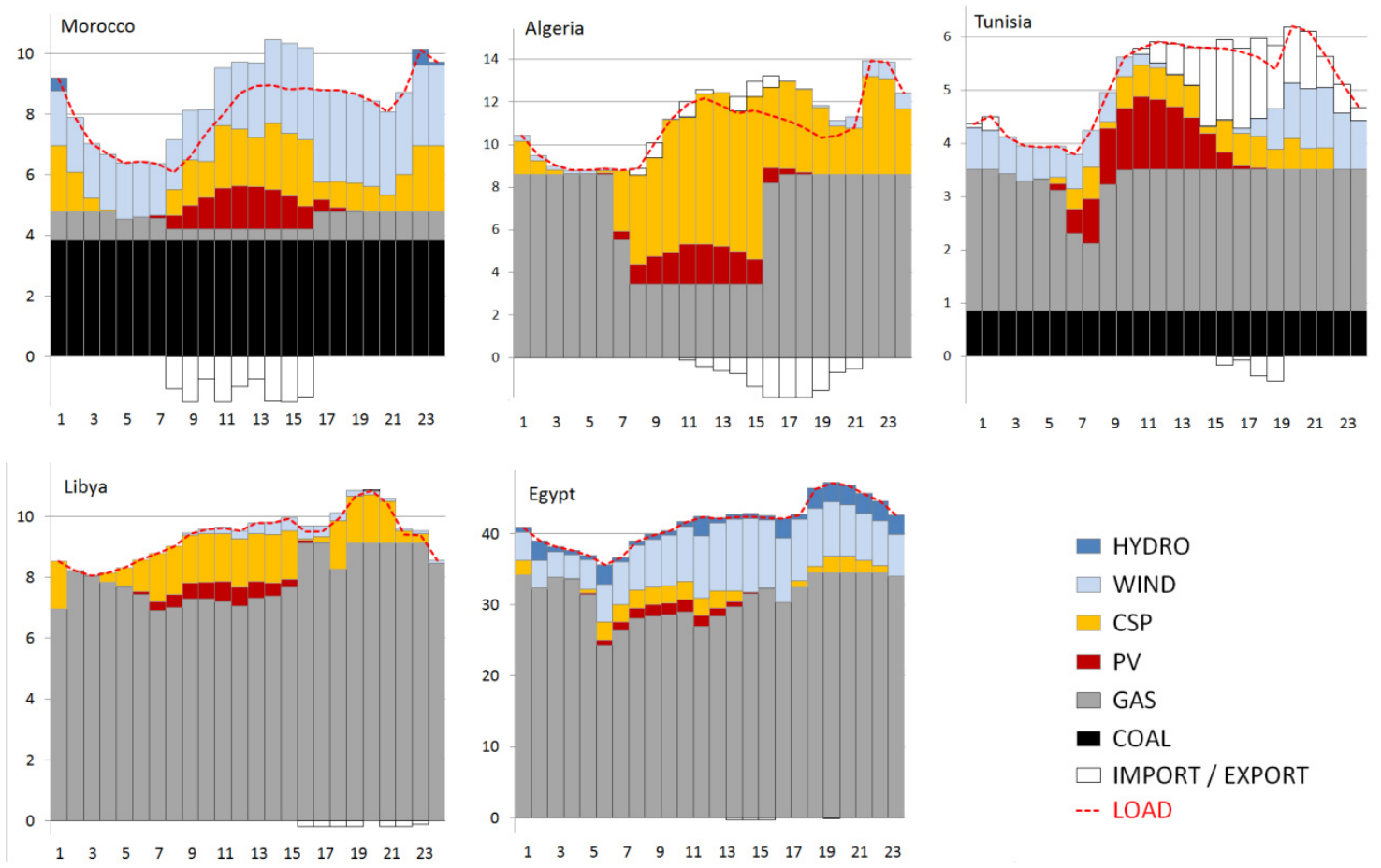

Figure 4. Dispatch pattern (in MW) for the five North African model regions on a summer day in 2030. "Mixed capacity and import reliance" scenario.

As explained above, power export affinity increases if the marginal system costs of a model region are lower than in other regions. This is usually the case when only inexpensive intermediary or base-load power plants need to be dispatched, e.g. at times of low electricity demand (at night and in the early morning), or when RES-E power generation significantly reduces the residual load that needs to be covered by conventional power plants. In the present example (see Figure 4, top), such an event can be observed in Morocco and Algeria, where a temporary high penetration of wind and solar power reduces the output of gas power stations and enables electricity exports - even during the mid-day demand peak. In both cases, significant exports are the result. Conversely, the proneness to imports rises when high electricity demand meets low domestic renewable energy output. This is, in the given example, the case in Tunisia, where electricity imports are needed to cover the high residual demand in the afternoon and evening. A special feature -likewise observed in Tunisia, but also in Algeria - is simultaneous import and export of electricity. Such electricity transits can occur when a model region exhibits lower generation costs compared with one region, while they are higher in comparison with the other region. 
Figure 5 depicts the cumulative installed generating capacities (in MW) and power generation (in TWh) in all five North African model regions until 2030. It can be seen that despite the countries' renewable power goals, the bulk of the North African power supply in 2030 will still rely on natural gas, apart from a minor share of coal-fired power provided by steam coal power plants in Morocco and Tunisia. RES-E generation reaches $141.2 \mathrm{TWh}$, totaling approximately $24 \%$ of the five countries' total demand of 584.4 TWh in 2030 .
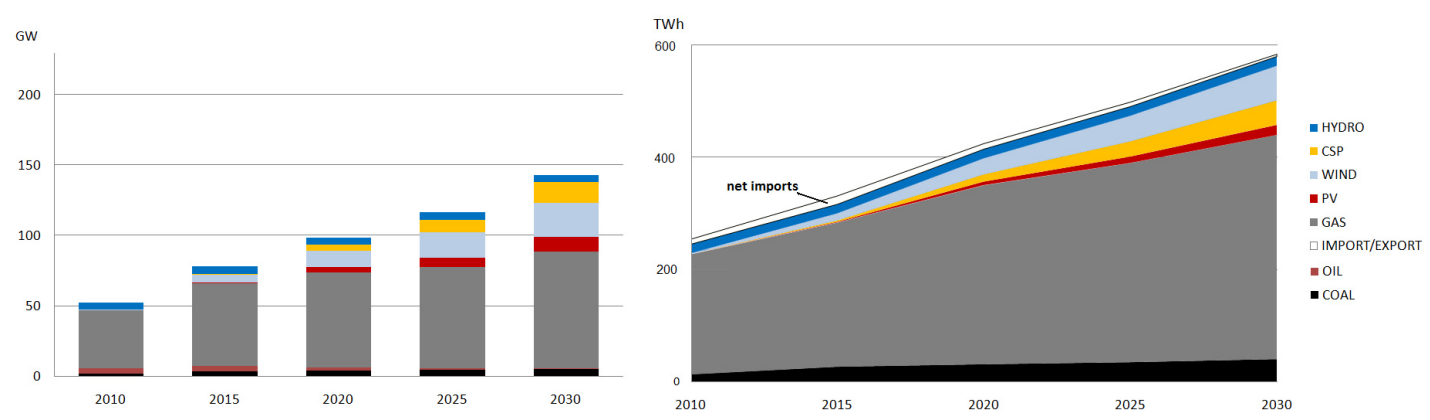

Figure 5. Cumulative installed capacities (left) and generation (right) of the five North African countries in the "mixed capacity and import reliance" scenario.

Looking at the electricity exchanges of North Africa with its satellite regions, it is noteworthy that the construction of trans-Mediterranean interconnectors apparently constitutes a signal for electricity transfers from Europe to North Africa - and not the other way around. Although the net North-South electricity flows of 4.3 TWh observed in the baseline scenario are comparatively small, this nevertheless points to a remarkable phenomenon that needs to be considered when designing trans-continental electricity interconnectors. That is, North African countries could be (at least temporarily) inclined to import rather than to export electricity from Europe on the transition pathway toward integrated EU-MENA power supply schemes.

\subsection{Increased RES-E penetration}

The outcome of the previous paragraph has shown that the power supply pattern in a North African integration scenario -in which the region reaches around 24\% RES-E penetration by 2030 - is not (yet) enough to trigger power exports from South to North. In this section, it shall be explored whether increased RES-E penetration could reverse this situation, and if so, what level of penetration would be required. To this end, additional model runs were carried out, simulating higher RES-E shares, reaching up to $50 \%$ of the overall North African 
demand by 2030. It is assumed that the additional capacity needed to fulfill these goals will be allocated according to a technology-neutral, least-cost integrated planning approach. It is additionally assumed that regardless of the North African RES-E capacity upgrades, the satellite regions' renewable expansion plans remain unaltered.
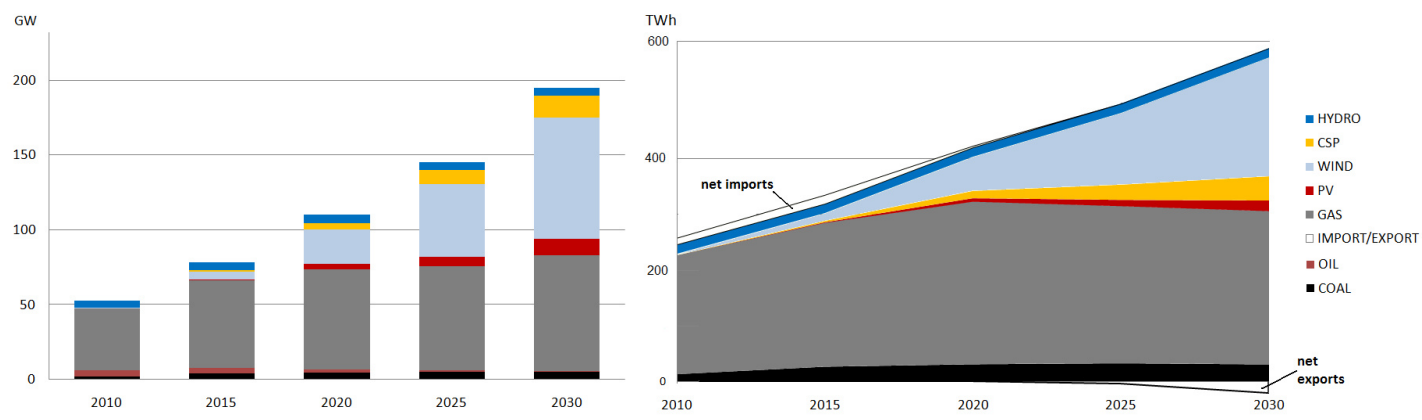

Figure 6. Cumulative capacities (left) and generation (right) in the case of 50\% RES-E penetration in North Africa until 2030.

The results for the 50\% penetration case are shown in Figure 6. Here, the least-cost approach significantly favors wind power (in comparison to CSP and PV technology) to be installed mainly in Egypt, Morocco and, to a lesser extent, Tunisia. As a second result, a shift in the exchange pattern between North Africa and its satellite regions can be observed: North African countries actually become net exporters of electricity, but only from 2025 onward, and only if their RES-E generation exceeds $>40 \%$ of their domestic demand. This result qualitatively confirms a previous finding by Haller et al. (2012), where net transmission flows from MENA to Europe were likewise observed only at relatively late stages of the transformation process - by 2030 - when high RES-E integration levels are reached.

Figure 7 illustrates the extent to which high RES-E penetration is a prerequisite for enabling net electricity flows out of North Africa into the satellite regions. In addition to the $50 \%$ and the $24 \%$ penetration, the analysis also explores exports under a $40 \%$ penetration scenario as well as the case of total disregard of the national RES-E goals (no further additional RES-E capacity until 2030, 0\%). 


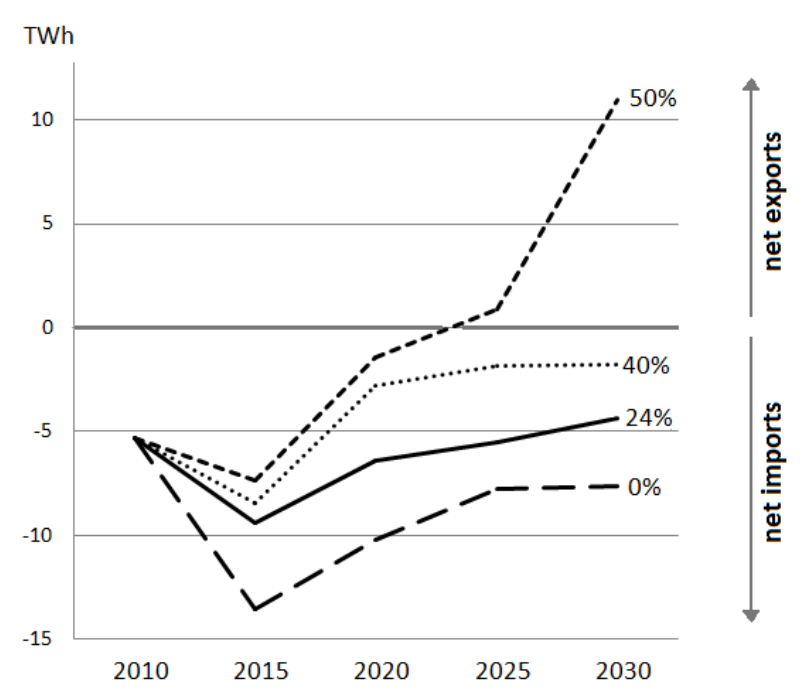

Figure 7. Net electricity exchanges of North Africa with the satellite regions depending on different RES-E penetration ambitions by 2030 . The $24 \%$ penetration represents the scenario in which the North African countries reach their current RES-E goals ("mixed capacity and import reliance scenario").

In all RES-E expansion scenarios, the construction of new trans-Mediterranean interconnectors in 2015 would initially lead to increased net electricity flows from Europe into the North Africa model regions. These North-South flows partially decrease in the following periods, as North Africa catches up with the construction of its own power plants both renewable and non-renewable. But, in the overall picture, net imports only vanish in the very high 50\%-RES-E penetration scenario, in which North Africa would be able to export around 10.9 TWh.

The finding that such great RES-E integration efforts are required before the North African region could realize first exports raises doubts about whether the paradigm of competitive, integrated EU-MENA electricity markets actually provides the right framework for enabling South-North electricity transfers. If this is an actual priority for Mediterranean politics, then it appears, in the short term, more conducive to improve the conditions for particular, 'organized' export projects (e.g. through bi- or multilateral off-take agreements for renewable power) than to wait for the market forces to leverage the comparatively better renewable energy resources in the South.

\subsection{Sensitivities}

It is known that simulations of dispatch and investment models covering long time periods are generally prone to sensitivities over technical and economic input parameter assumptions. An 
analysis of such sensitivities, therefore, deserves special attention - all the more so since the complexity of the model (which covers a high number of interconnected regions) increases the uncertainties. By carrying out test runs, the model results were checked for sensitivities regarding electricity demand, increased capital costs for power generation technologies, lower learning rates (and thus slower cost reductions) for renewable technologies and different fuel price scenarios. Generally, these sensitivities remain moderate, especially if the input parameter modifications are equally applied to all model regions. The strongest impact results from heterogeneities of cost input parameter between the model regions. The variable costs of electricity generation are first and foremost decisive: Even small interregional disparities in this area were able to significantly distort the outcome of the simulated generation infrastructures and inter-country transmission topologies. The following two examples briefly demonstrate that such cost disparities could very well constitute an issue in practice.

\subsubsection{Impact of fuel costs disparities}

Contrary to the widely applied approach of using opportunity costs for fossil fuels in power system modeling, it could be argued that due to strategic behavior (for political or social reasons) certain North African countries might become inclined to ignore this economic rationale. Already today, many MENA countries with rich hydrocarbon reserves subsidize energy inputs to their power systems (MED-EMIP, 2010), and some governments might regard future international electricity interconnectors as an additional channel to commercialize natural gas abroad -with the motive of stimulating local investments in the electricity sector and the creation of jobs. In order to get an idea of the impacts of such behavior, further simulations were carried out, assuming a scenario in which the three North African gas-heavyweights, Egypt, Algeria and Libya, 'subsidize' their domestic gas power plants with natural gas at prices $20 \%$ lower than the opportunity costs indicated in Table 5 . Even with this moderate price reduction ${ }^{10}$, the model results are tremendous: all three countries would become major electricity exporters, not only supplying electricity to their North African neighbors, but also substantially increasing electricity transfers to the European and the eastern Mediterranean satellite regions. In 2030, the NTC capacity to the North would increase to $11 \mathrm{GW}$, with net exports totaling around $67 \mathrm{TWh}$. Although it seems unlikely that such a scenario would actually materialize to the extent shown, the results nevertheless

10 Given the actual natural gas production and transport costs (OME, 2010), this price level would still be largely profitable for the North African gas producers. 
indicate that gas-producing countries might become interested in using their market power to 'export' natural gas via electricity interconnectors. The question of whether this possible motivation - and maybe not so much the desire for renewable energies - could shape the transformation of electricity systems in North Africa and its interconnections with Europe requires additional research, very likely including a combined analysis of the EU-MENA electricity and gas markets.

\subsubsection{Impact of potential carbon leakage effects}

A similar effect of variable cost disparities can be expected if the postulate of homogenous carbon costs for all model regions (see section 4.3.3) was removed. Currently, contrary to Europe, none of the North African or Middle Eastern countries applies carbon costs in their power systems. If no particular measures are taken, carbon leakage would likely occur on future interconnected EU-MENA electricity systems. This possibility was simulated by applying zero carbon costs for North Africa, the East Mediterranean model region, and Turkey, while carbon costs were held unaltered for the European model regions. As in the previous case, a substantial distortion of the results was observed: dramatically increasing fossil power generation in North Africa, the East Mediterranean countries and Turkey, and huge net electricity transfers (around 280 TWh per year) from these regions into Europe in 2030.

This drastic outcome underscores that measures to counter carbon leakage effects are actually imperative if stronger trans-Mediterranean electricity integration is envisaged. The European Commission already has taken a similar position with regards to the future evolution of the European and North African network, stating that "further interconnection must be accompanied by safeguards to prevent risks of carbon leakage through power imports to increase" (European Commission, 2010).

\section{Discussion}

Interconnecting different power systems with heterogeneous supply and demand structures generally offers important economic benefits and efficiency gains. This theorem also holds true for the North Africa power markets, as simulations with a linear optimization model demonstrate in this study. The five North African countries -currently feebly interconnected, and challenged with soaring electricity demand and ambitious renewable energy targets - 
could achieve important cost savings until 2030 if they were to set up more powerful transmission capacities among themselves and with their European and Middle Eastern neighbors. However, these economic benefits can only be realized if all countries show a true willingness to cooperate. Political concerns, e.g. of becoming too dependent on foreign electricity generation, can impede the ambition to upgrade transnational interconnectors and hence reduce the economic gain of system integration. A noteworthy aspect is that the North African region, despite having more competitive RES-E resources, tends to remain a net importer of electricity from Europe at least until 2030 (the time horizon of this study). The reason for this import bias is that Europe's power mix still includes important shares of cheaper base-load generation, rendering marginal electricity production costs lower than in the gas-based North African power systems. Only by assuming a very high RES-E penetration can moderate exports to Europe be achieved. This finding indicates that the paradigm of integrated, competitive electricity markets alone might not be enough to trigger electricity exports to Europe in the short run. Additional incentives or regulatory measures are required to enable first RES-E transfers from North Africa to Europe. A further finding of the analysis is that important distortions of the North African and trans-Mediterranean power exchange patterns can be expected if certain countries demonstrate strategic behavior by strengthening their domestic power sector's competitiveness with artificially low-priced fossil fuel supplies. Similar imbalances also occur if carbon leakage, due to heterogeneous climate policies between different regions in the Mediterranean, could not be suppressed by regulatory measures. The promoters of large, integrated EU-MENA power supply schemes should consider these effects, and develop, to the greatest extent possible, a level playing field conducive to a sustainable expansion of renewable energies in the North African region.

\section{Acknowledgement}

This work has received substantial input from discussions with members of the Desertec University Network (DUN) during a workshop held in Tunis in September 2012. The author likewise acknowledges comments of Kornelis Blok (Utrecht University) and Thomas Fink (Wuppertal Institute), as well as the kind support of Claire Thomas (Transvalor) providing the solar radiation data for this study. 


\section{References}

AfDB, 2012. Unlocking North Africa's Potential through Regional Integration: Challenges and Opportunities. African Development Bank (AfDB) Group, Tunis.

African Manager, 2012. Tunisie - Energies renouvelables: 30\% de la production énergétique d'ici 2030. <www.africanmanager.com/143028.html>. Tunis.

Algiers Declaration, 2010. Intégration progressive des marches de l'électricité de l'Algérie, du Maroc et de la Tunisie dans le marché intérieur de l'électricité de l'Union Européenne. $1^{\text {ère }}$ Réunion du Conseil Ministériel. Déclaration d'Alger 20 août 2010. In : Equilibres $\mathrm{N}^{\circ} 10$, p.10. Commission de Régulation de l'Electricité et du Gaz (CREG), Algiers. $<$ http://www.creg.gov.dz/>

AUPTDE, 2012. Electrical Power Stations in the Arab Countries. Arab Union of Producers, Transporters, and Distributors of Electricity (AUPTDE), Amman. $<$ http://www.auptde.org/>

Brand, B., et al., The value of dispatchability of CSP plants in the electricity systems of Morocco and Algeria. Energy Policy (2012), http://dx.doi.org/10.1016/ j.enpol.2012.04.073

Brand, B., Zingerle, J., The renewable energy targets of the Maghreb countries: Impact on electricity supply and conventional power markets. Energy Policy (2010), doi:10.1016/j.enpol.2010.10.010

Capros, P., Mantzos, L., Tasios, N., Vita, A.D., Kouvaritakis, N., 2010. EU Energy Trends to 2030 - Update 2009. Technical Report. European Commission, Directorate-General for Electricity. Brussels

Czisch, G., 2005. Szenarien zur zukünftigen Stromversorgung. Kostenoptimierte Variationen zur Versorgung Europas und seiner Nachbarn mit Strom aus erneuerbaren Energien. University of Kassel.

Dii, 2012. Desert Power 2050. Perspectives on a Sustainable Power System for EUMENA. Munich, June 2012.<www.dii-eumena.com>

ECN, 2006. Barriers and drivers of new interconnections between EU and non-EU electricity systems. Economic and regulatory aspects. $<$ http://www.ecn.nl/publications/ECN-C-06-006>. Petten, May 2006.

ECN, 2011. Renewable energy projections as published in the national renewable energy action plans of the European member states. $<$ http://www.ecn.nl/publications/ECN-E-10-069>. Petten, November 2011.

ENTSO-E, 2012. European Network of Transmission System Operators for Electricity, Brussels, 2012.<www.entsoe.eu/resources/> 
European Commission, 2010. Energy infrastructure priorities for 2020 and beyond - A Blueprint for an integrated European energy network. (COM(2010) 677 final. Brussels.

EWI/Energynautics, 2011. Roadmap 2050 - a closer look: Cost-efficient RES-E penetration and the role of grid extensions. Cologne, October 2011

Ghiles, F., 2010.The Maghreb refuses to share. Le Monde Diplomatique 02/2010. Paris.

GIZ, 2011. Etude Stratégique du Mix Energétique pour la Production d'Electricité en Tunisie, Tunis 2011.

Haller, M., et al., Decarbonization scenarios for the EU and MENA power system: Considering spatial distribution and short term dynamics of renewable generation. Energy Policy (2012), http://dx.doi.org/10.1016/j.enpol.2012.04.069

Helioclim, 2012. SoDa Database. <http://www.soda-is.com/eng/helioclim/>. Paris

IEA, 2011. International Energy Agency World Energy Outlook (WEO) 2011.Paris.

Kost, C., Schlegel, T., 2012. Studie Stromgestehungskosten erneuerbare Energien. Fraunhofer Institut für Solare Energiesysteme (ISE), May 2012, Freiburg.

Masen, 2012. Moroccan Agency for Solar Energy. Rabat. <www.masen.ma>

MED-EMIP, 2010. Medring Update Study, Vol I-IV. Euro-Mediterranean Energy Market Integration Project, Final Draft, April 2010. <www.medemip.eu>

Medreg, 2012. Association of Mediterranean Regulators for Electricity and Gas, Milan. $<$ http://www.medreg-regulators.org/>

MEM, 2012. Programme des Energies Renouvelables et de l'Efficacité Energétique. Ministère de l'Energie et des Mines, <http://www.memalgeria.org/francais/index.php?page=enr $>$. Algiers.

Mercados, 2011. Guide des outils de planification du système électrique pour améliorer l'intégration de l'énergie renouvelable. Application à la région du Maghreb. Madrid, November 2011.

MERRA, 2012. Modern Era Retrospective Analysis for Research and Application. NASA, 2012. <http://gmao.gsfc.nasa.gov/research/merra/intro.php>

NREA, 2012. New and Renewable Energy Authority of Egypt.<www.nrea.gov.eg>. Cairo.

NREL, 2012. System Advisor Model, version 2012.5.11. <https://sam.nrel.gov/>. Golden, Colorado.

OME, 2011. Mediterranean Energy Perspectives 2011. Observatoire Méditerranéen de 1'Energie. Nanterre, 2011. <www.ome.org>

ONE, 2008. Quand l'énergie vient du vent. Office National d'Electricité. Casablanca. 
PWMSP, 2012. Paving the Way for the Mediterranean Solar Plan.Roadmaps and national benchmarking reports. <www.pavingtheway-msp.eu>

Realisegrid, 2010. Work Package report WP1: Performances and costs of innovative grid technologies Comparison of $\mathrm{AC}$ and $\mathrm{DC}$ technologies for long-distance interconnections (D1.3.3). Dortmund, 2010.

REAOL, 2012. Renewable Energies in Libya - the future prospective. Presentation by Renewable Energy Authority of Libya, Oct. 2011. Cairo.

Sander+Partner, 2012. <http://www.sander-partner.com/en/products/mint.html $>$. Munich.

Swider, D., Weber, C. 2005. The effects of stochastic electricity market modeling on estimating additional costs of intermittent RES-E integration.IAEE European conference 2005, Stuttgart.

TEİAŞ, 2012. Annual report 2011. Turkish Electricity Transmission Corporation. Ankara, 2012. <www.teias.gov.tr>

TYNDP, 2012. 10-Year Network Development Plan. European Network of Transmission System Operators for Electricity (ENTSO-E), Brussels, July 2012. $<$ www.entsoe.eu/system-development/tyndp/tyndp-2012/>.

Younis, H., 2012. New plan to generate 3,500 megawatts of solar energy began. Egypt State Information Service. <www.sis.gov.eg/En/Story.aspx?sid=62037>. Cairo. 